\title{
Dolgu Duvarların Betonarme Binaların Doğal Titreşim Periyotları Üzerindeki Etkisinin İncelenmesi
}

\author{
${ }^{* 1}$ Abdullah Yiğit, ${ }^{2}$ Barış Erdil ve ${ }^{3}$ İsmail Akkaya \\ ${ }^{1}$ Van Yüzüncü Yıl Üniversitesi, Fen Bilimleri Enstitüsü, İnşaat Mühendisliği Ana Bilim Dalı, Türkiye \\ ${ }^{2}$ Van Yüzüncü Y1l Üniversitesi, Mühendislik Fakültesi, İnşaat Mühendisliği Bölümü, Türkiye \\ ${ }^{3}$ Van Yüzüncü Y1l Üniversitesi, Mühendislik Fakültesi, Jeofizik Mühendisliği Bölümü, Türkiye
}

\begin{abstract}
Özet
Tuğla, gaz beton, briket vb. inşaat malzemeleri ile kaplama veya bölme amaçlı kullanılan dolgu duvarlar, betonarme yapılarla birlikte yaygın olarak kullanılmaktadır. Deprem yönetmeliklerinde dolgu duvar taşıyıcı eleman olarak her ne kadar kabulü onanmasa da veya sadece ağırlık olarak yapıya bir etkisi olduğu kabul edilse de y1llarca yapılan analitik ve deneysel çalışmalar neticesinde dolgu duvarların betonarme yapıların davranışına önemli bir etkisi olduğu belirlenmiştir. Bu çalışmada dolgu duvarlı gerçek betonarme binalar ele alınmıştır. Bu binalar üç boyutlu olarak modellenerek dinamik analizleri yapılmıştır. Analizler sonucunda binaların dolgu duvarlı ve dolgu duvarsız modellerine ait doğal titreşim periyot değerleri bina planının her iki doğrultusu için elde edilmiştir. Elde edilen doğal titreşim periyotları daha sonra binalardan alınan mikrotremor ölçümleri ile karşılaştırılmıştır. Dolgu duvarlı olarak analiz edilen binaların doğal titreşim periyotlarının önemli düzeyde azaldığı ve mikrotremor ölçümlerine daha yakın değerler elde edildiği görülmüştür.
\end{abstract}

Anahtar kelimeler: Dolgu duvar, Betonarme bina, Doğal titreşim periyodu, Mikrotremor

\begin{abstract}
Infill walls constructed from brick, porous concrete block, briquette etc., which are used for the purpose of coating or partition, are commonly used with reinforced concrete structures. Although infill walls are only considered to be a load for the structure and not regarded as a structural member in the seismic codes, it has been determined that the effect of the infill walls on the behavior of reinforced concrete structures is great. In this study, reinforced concrete buildings with infill walls are taken into account. 3D models of the buildings were created and dynamic analysis was performed. Natural vibration periods for both principal directions of the buildings with or without infills were obtained. Then, natural vibration periods were compared with the microtremor measurements taken from these sample buildings. It was found that infill walls reduce the natural vibration periods of the buildings and the values for the models considering infill walls become closer to the microtremor recordings.
\end{abstract}

Keywords: Infill wall, Reinforced concrete building, Natural vibration period, Microtremor

${ }^{*}$ Corresponding author: Address: Van Yüzüncü Yll Üniversitesi, Fen Bilimleri Enstitüsü, İnşaat Mühendisliği Ana Bilim Dalı, Türkiye 


\section{Giriş}

Binaların doğal titreşim periyodu (kısaca periyot), yapıların deprem performansının değerlendirilmesinde ve eşdeğer deprem yükünün hesabında kullanılan en temel parametrelerden birisidir. Betonarme yapıların periyotları yapı kütlesine ve yapı rijitliğine bağlı olarak değişiklik göstermektedir. Bu nedenle, doğal periyot üzerinde değişiklik gösterebilen yapısal eleman olarak değerlendirilmeyen fakat yapı rijitliğine önemli bir katkısı olan dolgu duvarların varlığı göz ardı edilmemelidir.Yapılan çalışmalarda dolgu duvarların yapının rijitliğini artırdığı ve yapının yatayda ve düşeyde rijitlik dağılımlarını değiştirdiği belirtilmektedir [1]. Birçok ülkenin deprem standartları (Fransa, Kosta Rika, Cezayir, İsrail, Avrupa Birliği, Kolombiya, Filipin vs.) dolgu duvarların betonarme yapıların modellenmesinde hesaba katılmasını önermektedir[2]. Aksi takdirde sadece yükseklik veya kat sayısına bağlı olarak ampirik bağıntıların kullanılması doğal periyotların hesaplanmasında gerçeğe yakın sonuçlar vermemektedir.

Binalara etkiyen deprem yükü binaların doğal titreşim periyotlarından etkilenmekte olduğundan gerçeğe yakın periyotların belirlenmesi daha gerçekçi bina modellerin oluşturulmasına ve daha güvenilir binalar inşa edilmesine olanak sağlayacaktır. Çoğu Deprem Yönetmeliği'nde dolgu duvarın sisteme katkısı ihmal edildiğinden nispeten daha büyük periyotlar ve buna bağlı olarak da daha düşük deprem yükleri hesaplanarak binalar analiz edilmektedir. Deprem yükü azaltma katsayısı ile azaltılmış deprem yükleri, periyotların büyük hesaplanması ile bir kez daha azaltılmaktadır. 2011 Van Depremlerinde genel olarak yapısal elemanlarda az hasar gözlenmişken, dolgu duvarlarda ağır hasarlar tespit edilmiştir. Her ne kadar binalar istenen performansı sağlamış olsa da dolgu duvar hasarı neticesinde binaların deprem sonrası kullanımı güçleşmiş, yapı sahipleri binalarının güvenliğinden endişe duyar hale gelmiştir. $\mathrm{Bu}$ sebeple yapısal analizlerin daha gerçekçi yapılması, dolgu duvarların sisteme olan katkısının ihmal edilmemesi ve dolgu duvar hasarlarının yapısal analizlerde belirlenebilir olması gerekmektedir.

$\mathrm{Bu}$ çalışmada dolgu duvarların bina periyotları üzerine etkisi araştırılarak, yerinde alınan mikrotremor ölçümleri ile karşılaştırmalar yapılmıştır.

\section{Materyal ve Metot}

Van Yüzüncü Y1l Üniversitesi kampüsünde yer alan 10 adet dolgu duvarlı betonarme bina mevcut projeleri dahilinde ve mevcut beton basınç dayanımları esas alınarak bu çalışma kapsamında değerlendirmeye alınmıştır. Çalışmada kullanılan binalarda mikrotremor ölçümleri yapılarak binanın iki asal doğrultusunda doğal titreşim periyot değerleri tespit edilmiştir. Binaların dolgu duvarlı ve dolgu duvarsız üç boyutlu modelleri SAP2000 programı yardımıyla oluşturulmuştur[10].Dolgu duvar modellemesi yapılırken makro model sinıfında yer alan diyagonal eşdeğer basınç çubuğu metodu kullanılmıştır. Bu yöntemde dolgu duvar malzemesini temsil eden elastisite modülü, duvar basınç dayanımı, duvar birim hacim ağırlığı gibi parametreler için kullanılan değerler, deprem yönetmeliklerinde belirtilen ve bunun üzerine birçok araştırmacı tarafından kullanılan malzeme özellikleri incelenmiştir.Ardından parametreler incelenen binalardaki dolgu duvarları temsil edecek şekilde belirlenmiş ve dolgu duvarlı modeller oluşturulmuştur. 


\subsection{Dolgu Duvar Modeli}

Çeşitli inşaat malzemelerinden örülen dolgu duvarların betonarme çerçeveli yapılar üzerindeki etkilerini test etmek için makro ve mikro modeller olarak adlandırılan eşdeğer basınç çubuğu ve sonlu elemanlar yöntemleri kullanılmaktadır. Sonlu elemanlar metoduna göre dolgu duvarlar çubuk elemandan ziyade panel elemanlar olarak modellenmektedir. $\mathrm{Bu}$ yöntemi kullanmanın en önemli avantajı dolgu duvarların çerçeve sınırları içindeki davranışlarının incelenebilmesidir. Dolgu duvarlı çerçeve sistemleri için öne sürülen diğer yöntem olan eşdeğer basınç çubuğu metodu, dolgu duvarların çerçeve üzerindeki etkileri konusunda problemin çözümü için hem geometriksel hem de mekaniksel olarak uygun bulunmuştur. Ancak eşdeğer basınç çubuğu yönteminde dolgu duvarların davranış şekillerini incelemek mümkün değildir. Eşdeğer basınç çubuğu yönteminde literatürde bir, iki ve üç eşdeğer basınç çubuklu modeller önerilmiştir. Bütün modellerde çubukların modellenmesi için gerekli temel terimler olan çubuk genişliği (w), temas mesafesi (z) ve rijitlik katsayısı $\left(\lambda_{h}\right)$ ile ilgili çeşitli bağıntılar öne sürülmüştür. Yine temsil edilen dolgu duvarın imal edildiği malzeme özellikleri -elastisite modülü, malzeme basınç dayanımı ve birim hacim ağırlıkmodelleme aşamasında kullanılmaktadır. İlk olarak Polyakov[4] tarafindan ortaya atılan bu yöntemdeki kullanılan terimlerin kalibrasyonu için daha önceden dolgu duvarlı ve dolgu duvarsız betonarme çerçeveler üzerinde birçok deneysel çalışma yapılmıştır.

$\mathrm{Bu}$ çalışmada dolgu duvar modellemesi işleminde diyagonal eşdeğer basınç çubuğu metodu kullanılmıştır. Dolgu duvarlı betonarme binaların analizinde kullanılan iki ucu mafsallı diyagonal eşdeğer basınç çubuğu genişliği ve diyagonal uzunluğu şematik olarak Şekil 1'de verilmektedir.

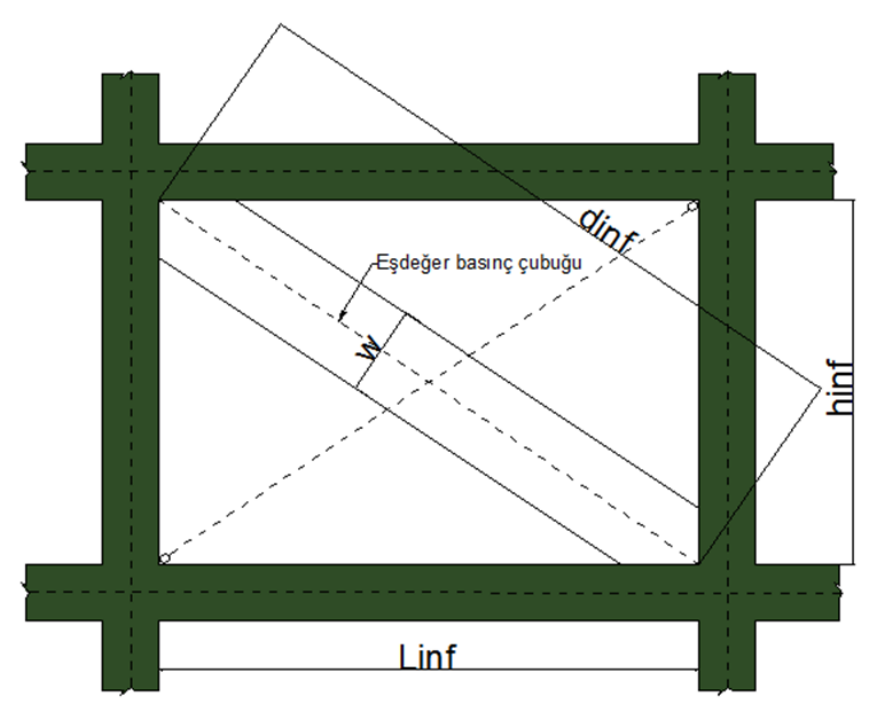

Şekil 1. Diyagonal eşdeğer basınç çubuğu modeli

Diyagonal eşdeğer basınç çubuğu genişliği (w) hesabı için Paulay ve Preistley[5] tarafindan geliştirilen ve Denk.1' de sunulan bağıntı kullanılmıştır

$w=0.25 * d_{\text {inf }}$ 
$d_{\text {inf }}=\sqrt{L_{i n f}^{2}+h_{i n f}^{2}}$

Denk.2'de $d_{\text {inf }}$, eşdeğer basınç çubuğunun diyagonal uzunluğunu; $L_{\text {inf }}$, iki kolon arasında kalan dolgu duvar elemanının net uzunluğunu; $h_{\text {inf }}$, alt ve üst kattaki kirişler arasında kalan dolgu duvar yüksekliğini belirtmektedir.

Pencere, kapı vb. nedenlerle bırakılan boşluklar dolgu duvar rijitliğini azaltıcı yönde etki etmektedir. Yapının modal rijitliğinin azalması yapının periyodunu arttırdığından boşluk varlığının dikkate alınması gerekmektedir. Bu çalışma kapsamında dolgu duvarlardaki boşluk miktarının eşdeğer basınç çubuğu modeline yansıtılması için Bertoldi [6]'nin öne sürdüğü ve Denk.3'te verilen bağıntı kullanılmıştır. Bağıntıda $r_{a c}$, dolgu duvarlardaki boşluk miktarını; $A_{a}$, dolgu duvar alanının boşluk alanına oranını; $A_{e}$, dolgu duvar uzunluğunun boşluk uzunluğuna oranını temsil etmektedir. Bu çalışmada boşluk miktarı için $r_{a c} \cong 0.4$ denkliği esas alınmıştır.

$r_{a c}=0.78 * e^{-0.322 * \ln A_{a}}+0.93 * e^{-0.762 * \ln A_{e}} \quad ; \quad r_{a c} \cong 0.4$

Diyagonal eşdeğer basınç çubuğu elemanları için elastisite modülü ve dolgu duvar basınç dayanımı parametreleri için FEMA-356' da [7] önerilen bağıntı ve esaslar referans alınmıştır. Elastisite modülü $\left(E_{\text {dolgu }}\right)$ için Denk.4'te ifade edilen bağıntı kullanılmıştır. Aynı zamanda dolgu duvar basınç dayanımı $\left(f_{\text {dolgu }}\right)$ için $4.1 \mathrm{MPa}$ değeri kullanılmıştır. Dolgu duvarlarda kullanılan tuğla malzemesinin birim hacim ağırlığ $8 \mathrm{kN} / \mathrm{m}^{3}$ olarak alınmıştır [8].

$E_{\text {dolgu }}=550 * f_{\text {dolgu }} \quad ; \quad f_{\text {dolgu }}=4.1 \mathrm{MPa}$

\subsection{Modelleme}

Çalışmada 10 farklı geometriye ve farklı kat sayısına sahip binaların yapısal çözümlemesi yapılmıştır. Bu binalar 1 adet 2 katlı, 1 adet 3 katlı, 6 adet 4 katlı ve 2 adet 5 katlı binalardan oluşmaktadır. Örnek binaların tümü perde duvar ve çerçeve taşıyıcı elemanlardan oluşmaktadır. Analizler sırasında Türkiye Bina Deprem Yönetmeliği (TBDY-2018) [3] esas alınmıştır. Referans alınan betonarme binaların yapısal analizi sırasında ele alınan konular aşağıda verildiği gibi izlenmektedir.

- Yapının üç boyutlu analizi için sonlu elemanlar modeli hazırlanmış olup kiriş ve kolon taşıyıcı elemanları çubuk elemanları (frame) kullanılarak modellenmiştir. Perde duvar ve döşeme taşıyıcı elemanları kabuk elemanlar (shell) kullanılarak modellenmiştir. Düşey taşıyıcı elemanlardan oluşan kolon ve perde duvar elemanlarının zemin ile etkileşimde bulunan alt uçları ankastre mesnet ile bağlanarak yatay ve düşey ötelenmelere karşı tutulu hale getirilmiştir.

- Taşıyıcı sistemlerin tanımlandığı elemanların her bir ucu 6 serbestlik dereceli bilinmeyenle bağlantı düğüm noktaları ile kenetlenmiştir.

- Yapının hizmet ömrü boyunca maruz kaldığı düşey yüklerin belirlenmesinde TS498 esas alınmıştır[9]. Belirlenen zati ve hareketli yükler uygun yük halleri kullanılarak yapı üzerine aplike edilmiştir. 
- Kat kütlelerinin hesabında $(\mathrm{G}+\mathrm{n} * \mathrm{Q})$ kombinasyonu kullanılmıştır. Modellerde kullanılan hareketli yük katılım katsayısı (n) temsili binaların kullanım amacı okul olduğu için 0.6 alınmıştır.

- Eğilme etkisindeki betonarme elemanlarda çatlamış kesite ait etkin eğilme rijitlikleri(EI $\left.\mathrm{E}_{\mathrm{e}}\right)$ kolon, kiriş ve perde duvar elemanları için kullanılmıştır. Kiriş ve perde taşıyıcı elemanlar için $(\mathrm{EI})_{\mathrm{e}}=0.35(\mathrm{EI})_{\mathrm{o}}$, kolon elemanları için $(\mathrm{EI})_{\mathrm{e}}=0.70(\mathrm{EI})_{\mathrm{o}}$ kullanılmıştır.

- Her kattaki döşemelerin konumlarına göre her kat için tüm düğüm noktalarına rijit diyafram atanmıştır.

- Mevcut elemanlar için malzeme dayanımları ile ilgili tasarım yönetmeliklerinde verilen malzeme katsayıları kullanılmadan doğrudan mevcut malzeme dayanımları ve elastisite modülleri kullanılmıştır.

- Üç boyutlu modele dayalı analiz sonucunda yapıların asal eksenleri doğrultusundaki doğal titreşim periyotları tespit edilmiştir.

Referans alınan dikdörtgen geometrik özelliğe sahip betonarme binaların dolgu duvarlı ve dolgu duvarsız tipik modellerinden iki tanesi Şekil 2 ve Şekil 3'te verilmektedir.
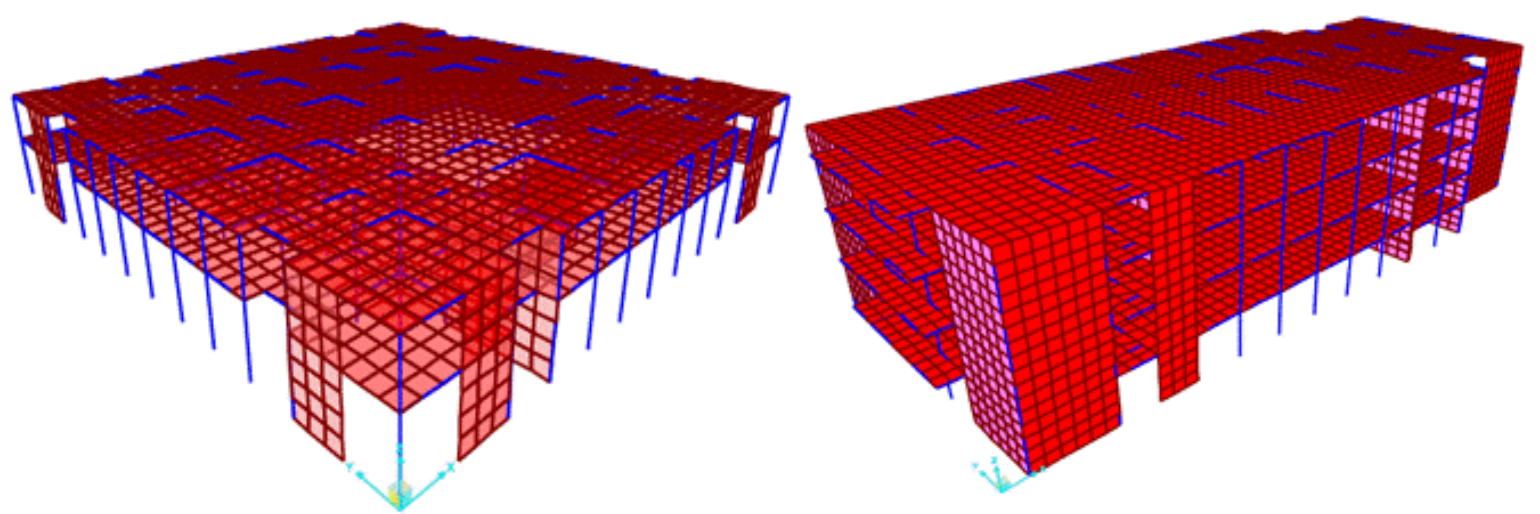

Şekil 2. Dolgu duvarsız tipik dikdörtgen şekilli betonarme yapıların 3D boyutlu gösterimi
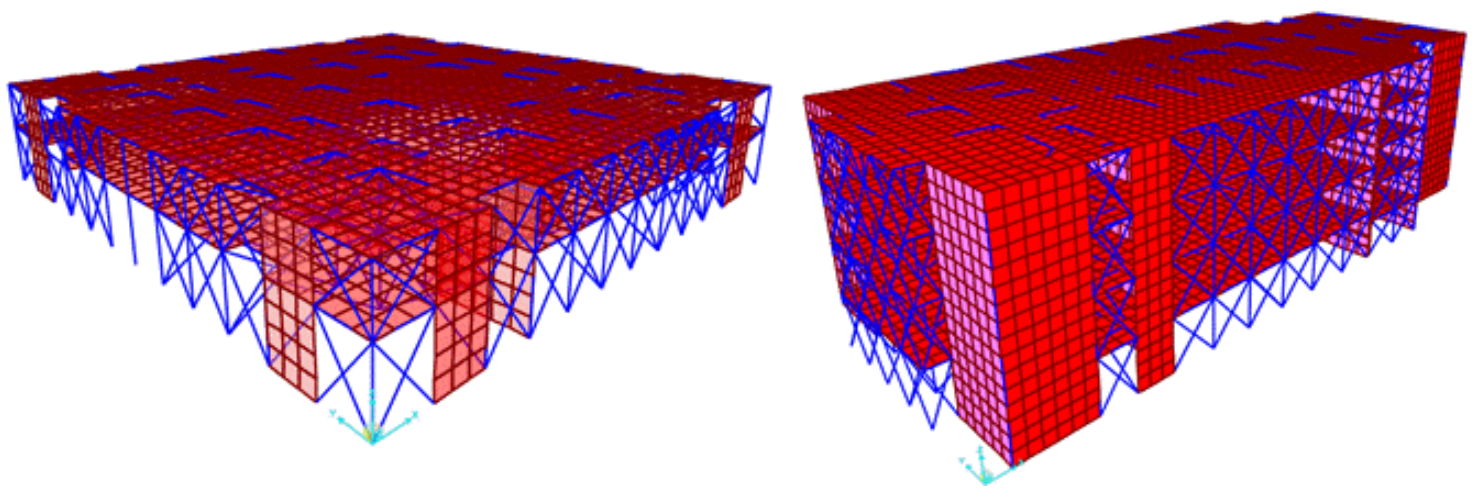

Şekil 3. Dolgu duvarlı tipik dikdörtgen şekilli betonarme yapıların 3D boyutlu gösterimi

Şekil 2 ve Şekil 3 'te sırasıyla örnek dolgu duvarsız ve dolgu duvarlı betonarme binaların sanal model tiplerinin üç boyutlu görüntüsü verilmektedir. Toplamda 10 adet dolgu duvarlı ve 
dolgu duvarsız betonarme bina modellenmiştir. İncelenen betonarme binaların her birinin plan uzunluğu uzun ve kısa doğrultularda birbirinden farklı değerlere sahip olmaktadır. Tüm binaların taşıyıcı eleman sistemleri perde duvar, kolon, kiriş ve döşemelerden oluşmaktadır. Her bir binanın toplam yüksekliği birbirinden farklı değerlerden oluşmaktadır.Binaların çerçeve sistemini oluşturan kolonların, plandaki yerleşim şekilleri ve boyutları iç ve diş akslardaki konumlarına göre birbirinden farklı pozisyonda olmaktadır. Kalınlığı tüm binalarda $30 \mathrm{~cm}$ olan perdelerin çoğu iki kolon arasına yerleştirilmiş ve aslına uygun bir şekilde modellenmiştir. Modele tabi tutulan tüm dolgulu ve dolgusuz betonarme yapıların döşeme kalınlıkları gerçek proje baz alınarak aslına uygun bir şekilde tanımlanması yapılmıştır. Taşıyıcı eleman olarak nitelendirilmeyen dolgu duvar elemanların kalınlığı(t), dolgu duvarların mevcut olduğu iç akslarda $15 \mathrm{~cm}$, diş akslarda ise $20-30 \mathrm{~cm}$ arasında değişmektedir. Tablo 1.'de örnek binaların yapısal ve taşıyıcı özelliklerini gösteren çizelge verilmektedir. Tablo 2.'de taşı1ıı sistem malzeme özellikleri her bir bina için verilmektedir.

Tablo 1. Örnek betonarme bina bilgileri

\begin{tabular}{cccccccc}
\hline \multirow{2}{*}{$\begin{array}{c}\text { Bina } \\
\text { No }\end{array}$} & \multirow{2}{*}{$\begin{array}{c}\text { Kat } \\
\text { sayıs }\end{array}$} & \multirow{2}{*}{$\begin{array}{c}\text { Yükseklik } \\
(\mathrm{m})\end{array}$} & & \multicolumn{2}{c}{ Bina plan uzunluğu $(\mathrm{m})$} & Perde duvar alanı $\left(\mathrm{m}^{2}\right)$ & \multirow{2}{*}{$\begin{array}{c}\text { Kolon alanı } \\
\left(\mathrm{m}^{2}\right)\end{array}$} \\
\cline { 5 - 7 } & 4 & 14.8 & 24.9 & 14 & 5.22 & 8.1 & 4.95 \\
2 & 4 & 13.5 & 17.5 & 17 & 4.92 & 4.38 & 3.24 \\
3 & 4 & 13.5 & 16 & 14 & 2.1 & 1.68 & 4.73 \\
4 & 4 & 13.5 & 17.5 & 17 & 4.92 & 4.38 & 3.24 \\
5 & 4 & 13.5 & 16 & 14 & 2.1 & 1.68 & 4.73 \\
6 & 4 & 13.5 & 34.3 & 17 & 8.4 & 8.4 & 4.3 \\
7 & 3 & 13.1 & 39.92 & 23.4 & 14.64 & 13.8 & 7.24 \\
8 & 2 & 7.5 & 28 & 24 & 7.5 & 3.5 & 7.52 \\
9 & 5 & 16 & 31.05 & 30.3 & 5.85 & 5.4 & 14.16 \\
10 & 5 & 16 & 31.05 & 30.3 & 5.85 & 5.4 & 14.16 \\
\hline
\end{tabular}

Tablo 2. Taşıyıcı sistem malzeme özellikleri

\begin{tabular}{cccc}
\hline Bina No & E (MPa) & fc (MPa) & G, (MPa) \\
\hline 1 & 17321 & 12 & 7217.08 \\
2 & 21800 & 19 & 9083.33 \\
3 & 21200 & 18 & 8833.33 \\
4 & 18000 & 13 & 7500 \\
5 & 18000 & 13 & 7500 \\
6 & 18000 & 13 & 7500 \\
7 & 18000 & 13 & 7500 \\
8 & 18700 & 14 & 7791.67 \\
9 & 18000 & 13 & 7500 \\
10 & 15800 & 10 & 6583.33 \\
\hline
\end{tabular}

\section{Bulgular ve Tartışma}

Dolgu duvarlı ve dolgu duvarsız betonarme binaların SAP2000 programında modellenmesi ile dinamik analiz sonucunda 10 adet binanın maksimum doğal titreşim periyotları elde 
edilmiştir. Şekil 4'te elastik analiz sonucu elde edilen periyot değerlerinin mikrotremor sonuçları ile karşılaştırması hem dolgu duvarsız hem de dolgu duvarlı modeller için verilmektedir. Şekil 4a'da dolgu duvarsız olarak modellenen binaların periyotları karşılaştırılmış iken, Şekil 4b'de dolgu duvar varlığının etkisi incelenmiştir.

Şekil 4a'dan görüleceği üzere dolgu duvar dikkate alınmadan yapılan modellerde hesaplanan periyotların mikrotremor sonuçları ile çok farklılık gösterdiği, yayılı bir dağılım elde edildiği görülmektedir. Ayrıca analizden elde edilen periyot değerlerinin mikrotremor sonuçlarından çok büyük olduğu, aradaki farkın \%19-67 arasında değiştiği ve ortalama olarak \%38 daha büyük olduğu belirlenmiştir.

Dolgu duvarın modellendiği durum dikkate alındığında binadaki rijitlik artışı ile birlikte periyotların küçüldüğü, analiz sonuçlarının mikrotremor sonuçlarına yaklaştığı, aradaki farkın \%3-6 arasında değiştiği ve ortalama \%1 hata ile periyotların hesaplandığı Şekil 4b'den görülebilir. Unutulmamalıdır ki bu çalışmada plan şekli yaklaşık dikdörtgen olan binalar ele alınmış ve kat sayısı en fazla beş alınmıştır. Karmaşık planlara sahip ve kat yüksekliği fazla olan binalarda daha farklı sonuçlar elde edilebilir.

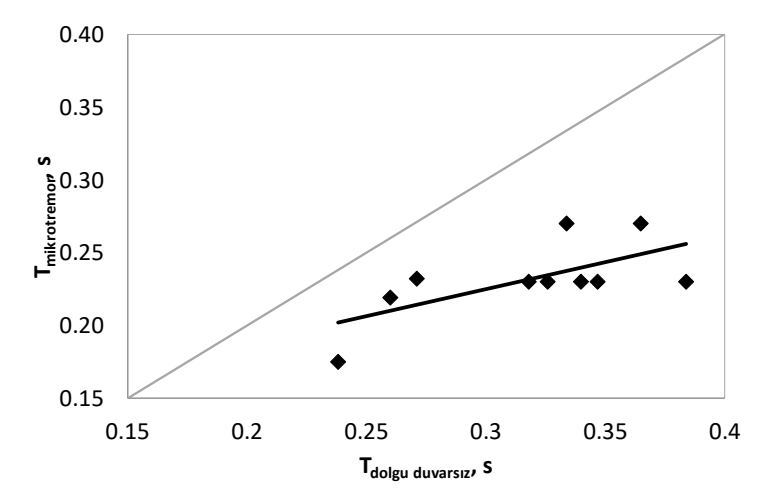

a) Dolgu duvarsiz periyotlar

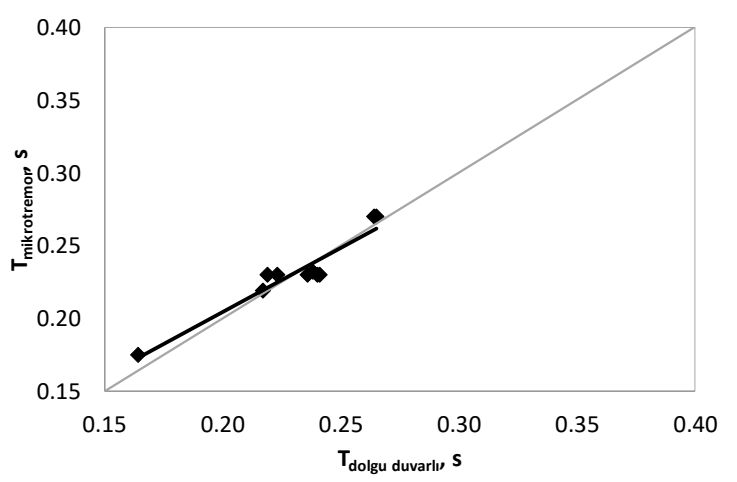

b) Dolgu duvarlı periyotlar Şekil 4. Analizden elde edilen periyotların mikrotremor periyotları ile karşılaştırması

\section{Sonuçlar}

Binalara etkiyen deprem yükü binaların doğal titreşim periyotlarından etkilenmekte olduğundan gerçeğe yakın periyotların belirlenmesi daha gerçekçi bina modellerin oluşturulmasına ve daha güvenilir binalar inşa edilmesine olanak sağlayacaktır. 2011 Van Depremlerinde genel olarak yapısal elemanlarda az hasar gözlenmişken, dolgu duvarlarda ağır hasarlar tespit edilmiştir. Her ne kadar binalar istenen performansı sağlamış olsa da dolgu duvar hasarı neticesinde binaların deprem sonrası kullanımı güçleşmiş, yapı sahipleri binalarının güvenliğinden endişe duyar hale gelmiştir. Bu sebeple yapısal analizlerin daha gerçekçi yapılması, dolgu duvarların sisteme olan katkısının ihmal edilmemesi ve dolgu duvar hasarlarının yapısal analizlerde belirlenebilir olması gerekmektedir.

$\mathrm{Bu}$ çalışma kapsamında 10 farklı bina modellenerek dinamik analizi yapılmıştır. Dolgu duvarsız olarak modellenen binaların mikrotremor sonuçlarından daha büyük periyotlara sahip olduğu, farkın \%19-67 arasında değiştiği belirlenmiştir. Binalar dolgu duvarlı olarak modellendiğinde ise periyotların mikrotremor sonuçlarına yaklaştığı ve farkın \%3-6 değerlerine kadar düştüğü gözlenmiştir.

Sonuç olarak dolgu duvarların modellerde dikkate alınması daha güvenilir bina modellerine imkan sağlayacaktır. 


\section{TEŞEKKÜR}

Bu çalışmaya maddi destek ile katkıda bulunan Van Yüzüncü Yıl Üniversitesi Bilimsel Araştırma Projeleri Koordinasyon Birimi'ne teşekkür ederiz.

\section{KAYNAKLAR}

[1] Dowrick D J. Earthquake Resistant Design for Engineers and Architects. 2nd ed. New York: John Wiley\&Sons; 1987.

[2] Sevil T, Baran M, Canbay E, Tuğla dolgu duvarların B/A çerçeveli yapıların davranışına etkilerinin incelenmesi; Deneysel ve kuramsal çalışmalar. International journal of engineering research and development 2010; Vol. 2, No.2, 35:42.

[3] TBDY, Türkiye Bina Deprem Yönetmeliği, Çevre ve Şehircilik Bakanlığı, Ankara, 2019.

[4] Polyakov S V. On the interaction between masonry filler walls and enclosing frame when loading in the plane of the wall. Translation in earthquake engineering, Earthquake Engineering Research Institute 1960; (EERI), San Francisco.

[5] Paulay T, Priestley M. Seismic Design of Reinforced Concrete and Masonry Buildings. New York: Jhon Wiley\&Sons, 1992.

[6] Bertoldi S H, Decanini L D, Santini S,Via G. Analytical Models in Infilled Frames. Proceedings of the 10th European Conference in Earthquake Engineering, Vienna, 1994.

[7] FEMA 365, Prestandard and Commentary For The Seismic Rehabilitation of Buildings, Federal Emergency Management Agency, 2000.

[8] Uysal K E, Özkul T A. Betonarme Binalarda Dolgu Duvarların Deprem Etkisi Altındaki Davranışının İncelenmesi, XVIII. Ulusal Mekanik Kongresi 2013, Manisa, Türkiye,644-655.

[9] TS498, Yapı Elemanların Boyutlandırılmasında Alınacak Yüklerin Hesap Değerleri, Türk Standartları Enstitüsü, Ankara, 1987.

[10] SAP2000, Computers and Structures, Inc., v.19.0.0, Structural Analysis Program, Berkeley, CA, USA, 2019. 